\title{
A AVALIAÇÃO DO AMBIENTE CONSTRUÍDO NOS CONJUNTOS HABITACIONAIS DE INTERESSE SOCIAL: DA INSERÇÃO URBANA AO DESENHO DA TIPOLOGIA
}

\author{
Camila Marques Paes da Cunha, Cristina Maria Perissinotto Baron \\ Universidade Estadual Paulista - UNESP, Departamento de Planejamento, Presidente Prudente, SP. E-mail: \\ kml camila@hotmail.com \\ Fundação de Amparo á Pesquisa do Estado de São Paulo (FAPESP).
}

\section{RESUMO}

Este trabalho analisa a implantação de dois conjuntos habitacionais de interesse social no Município de Presidente Prudente - SP, um realizado a partir do Plano Nacional de Habitação com a criação do Banco Nacional de Habitação (1964) e o outro a partir da Política Nacional de Habitação de Interesse Social (2005) com o Programa Minha Casa Minha Vida. Considerando o período de 30 anos entre a construção dos dois empreendimentos, tem-se como objetivo principal o estudo da relação da produção dos conjuntos habitacionais formais com a sua inserção na malha urbana, através da proposta de desenvolvimento de uma metodologia de análise, com as técnicas de Avaliação Pós-ocupação (APO). Cada um dos conjuntos é analisado considerando o fator de localização na malha urbana, as infraestruturas e o uso e ocupação do entorno, verificando a existência de serviços urbanos e a ocupação dos espaços destinados ao lazer.

Palavras-chave: Política Habitacional, Habitação De Interesse Social, Espaço Público, Desenho Urbano, Programa Minha Casa Minha Vida.

\section{THE ENVIRONMENTAL ASSESSMENT BUILT IN THE HOUSING PROJECTS OF SOCIAL INTEREST: THE URBAN INTEGRATION OF THE DESIGN TYPE.}

\begin{abstract}
This paper analyzes the implementation of two housing projects of social interest in the city of Presidente Prudente - SP, an accomplished from the National Housing Plan with the creation of the National Housing Bank (1964) and the other from the National Housing Policy Social Interest (2005) with the Program "Minha Casa Minha Vida". Considering the 30-year period between the construction of the two projects, we have as main objective the study of the relationship of the production of formal housing with their integration into the urban fabric, through the development proposal of a methodology, with Post-occupancy evaluation techniques. Each of the sets is analyzed considering the location factor in the urban, infrastructure and the use and occupation of the environment, checking for urban services and the occupation of spaces for leisure.

Keywords: Housing Policy, Social Interest Housing, Public Space, Urban Design, Program “Minha Casa Minha Vida".
\end{abstract}




\section{INTRODUÇÃO}

No país, a habitação de interesse social vem sendo abordada como uma necessidade de abrigo, sendo um direito garantido pela Constituição Federal de 1988, ficando em evidencia como uma necessidade vital para a convivência em sociedade. As discussões sobre a qualidade das moradias e as propostas dos conjuntos habitacionais produzidos no Brasil se iniciam nas décadas de 40 e 50. Porém, o contexto político, econômico e social da década de 60 fez com que se alterassem as propostas na área habitacional em relação à construção de conjuntos habitacionais, onde a quantidade passa a ser primordial e, prover habitação, significou fornecer apenas a casa. Planos e programas habitacionais priorizando a quantidade de unidades surgem a partir da Política Nacional de Habitação, implantada através da Lei no 4.380, de 21 de agosto de 1964, através do Plano Nacional de Habitação e da criação do Banco Nacional de Habitação - BNH, período este compreendido entre 1964-1986. (FINEP -GAP, 1983; 1984/1986)

Após o fechamento do BNH surge um período de reestruturação e acomodação das políticas habitacionais, onde se vê a Caixa Econômica Federal se reestruturando internamente para assumir os programas nas áreas de habitação e desenvolvimento urbano. Em âmbito estadual temos a Companhia de Desenvolvimento Habitacional e Urbano do Estado de São Paulo CDHU assumindo a responsabilidade pela produção de moradias e municipal a tentativa de solução do problema da falta de moradias através de programas de fornecimento de lotes urbanizados.

A aprovação do Estatuto da Cidade, em 2001 e a criação do Ministério das Cidades, em 2003, incorporando as cinco secretarias - Secretaria Nacional de Habitação, a Secretaria Nacional de Programas Urbanos, a Secretaria Nacional de Saneamento Ambiental e a Secretaria Nacional de Transporte e Mobilidade Urbana - constituíram-se em um novo patamar da política habitacional a partir do entendimento de que a questão deve ser tratada de maneira muito mais abrangente que a construção de casas, fato já apontado pelas políticas anteriores como também por experiências realizadas.

Destacam-se a elaboração da Política Nacional de Habitação - PNH, em 2004, na instituição do Sistema e do Fundo Nacional de Habitação de Interesse Social - SNHIS/FNHIS, em 2005, regulamentados pela Lei Federal n0 11.124, de 16/06/2005, na construção do Plano Nacional de Habitação (PlanHab), em 2008, e no desenvolvimento dos planos locais por estados e municípios PLHIS. Atualmente, tem-se o Programa Minha Casa Minha Vida (PMCMV), do governo federal lançado em abril de 2009, com o objetivo de promover a produção ou aquisição de novas unidades habitacionais, ou a requalificação de imóveis, para famílias com renda mensal de até 10 salários mínimos.

No período de 1964 a 1986 atuaram no Município de Presidente os seguintes órgãos habitacionais: Banco Nacional de Habitação (BNH), a Companhia de Habitacional Popular de Bauru (Cohab-Bauru), Instituto de Orientação às Cooperativas Habitacionais de São Paulo (INOCOOP), a Companhia de Desenvolvimento de São Paulo (CODESPAULO ${ }^{1)}$ ) e Companhia Prudentina de Desenvolvimento (PRUDENCO). De 1989 a 2005, tem-se a Companhia Regional de Habitação de Interesse Social (Cohab - CRHIS), de Araçatuba e a Companhia de Desenvolvimento Habitacional e Urbano do Estado de São Paulo (CDHU) construindo conjuntos habitacionais. (BARON; SILVA, 2014). Em 2009, são realizados os primeiros empreendimentos do programa Minha Casa Minha Vida.

A maioria desses empreendimentos são construídos em locais distantes, fornecendo péssimas condições de vida aos moradores, com a falta de serviços básicos e infraestrutura urbana. A partir disso, observa-se a necessidade de avaliar as situações dos conjuntos

\footnotetext{
${ }^{1}$ CODESPAULO: atual Companhia de Desenvolvimento Habitacional e Urbano do Estado de São Paulo (CDHU), teve inúmeros nomes e sofreu diversas alterações, iniciou suas atividades como Caixa Estadual de Casas para o Povo (CECAP), e, em 1989 passou a receber o nome definitivo de CDHU (Decreto 3005/89).
} 
habitacionais, quanto aos seus aspectos relacionados a qualidade urbana, no sentido de oferecer a população condições de cidadania. Desta forma, busca-se metodologias baseadas na Avaliação Pós Ocupacional (APO) para o desenvolvimento da pesquisa. A APO é definida, por Abiko e Ornstein (2002), como sendo um conjunto de métodos e técnicas de avaliação de desempenho aplicado no decorrer do uso de qualquer tipo de ambiente construído, onde, pretende-se aferir e diagnosticar, levando em consideração o parecer de especialistas e as necessidades e/ou níveis de satisfação dos usuários finais destes ambientes.

Os conjuntos habitacionais analisados neste trabalho são: Vila Nova (Inocoop), de 1979 e Jardim Panorâmico, de 2009. Busca-se verificar os elementos que possibilitam a consolidação dos mesmos na malha urbana, uma vez que o Inocoop se encontra totalmente consolidado e o Jardim Panorâmico em uma área ainda carente de serviços urbanos.

Como objetivo geral deste trabalho, tem-se o estudo da relação da produção dos conjuntos habitacionais formais com a sua inserção na malha urbana, através da proposta de desenvolvimento de uma metodologia de análise, com as técnicas de Avaliação Pós-ocupação (APO). Os objetivos específicos são: identificar a malha urbana existente no momento de implantação do conjunto habitacional e a situação atual; analisar a infraestrutura urbana e os serviços urbanos disponíveis; identificar as características das tipologias habitacionais, espaços livres, áreas institucionais, acessos e entorno próximo.

\section{METODOLOGIA}

Para essa pesquisa busca-se estabelecer parâmetros para uma avaliação pós- ocupacional baseada em questões urbanísticas, no sentido dos serviços urbanos oferecidos, assim como a infraestrutura e equipamentos urbanos, enfatizando a relação da localização do conjunto habitacional com o tecido urbano e as atividades existentes.

Quanto ao levantamento dos conjuntos habitacionais estudados, também foram destacados a identificação da tipologia habitacional; implantação; a relação das tipologias habitacionais e espaços públicos; sistema viário, infraestrutura executada.

Foram selecionadas duas escalas de análise, baseadas em Ferreira (2012): a escala da inserção urbana, relacionando o conjunto e o bairro, inseridos na cidade, verificando aspectos como acessibilidade e serviços urbanos e a escala da implantação, relacionando o conjunto ao seu entorno imediato, como a integração das habitações, vegetação, área de lazer, espaço de circulação. Ferreira (2012) também analisa a escala da unidade habitacional, a qual não é o foco dessa etapa do trabalho.

É importante ter em vista que as escalas se inter-relacionam e que a garantia de moradia de qualidade não está apenas na boa inserção urbana ou na boa implantação, assim como também não depende somente de correta solução tipológica ou tecnológica, isoladamente: "a qualidade urbanística e arquitetônica está na boa relação entre as três escalas, em diálogo com o contexto socioespacial do qual o empreendimento faz parte" (FERREIRA, 2012). Segundo o autor, é possível notar que grande parte dos empreendimentos habitacionais não verificam boas soluções para a escala da inserção urbana: ao observar o espraiamento urbano, segregação socioespacial, grandes vazios urbanos, bairros monofuncionais.

Portanto, baseado nas observações do autor, foi definida na metodologia os seguintes levantamentos: do traçado da implantação; das áreas de lazer e institucionais, assim como áreas verdes, em projeto e executadas; do uso e ocupação dos lotes. Com isso, busca-se encontrar relações do conjunto com o restante da cidade, entendendo como se dão os deslocamentos e atividades realizadas a partir da inserção do conjunto na malha urbana. Temos como ponto central, do levantamento das características urbanas, o centro da cidade, pois, conforme Sposito (2001), o centro da cidade de Presidente Prudente é onde acontecem a grande maioria das principais atividades comerciais e de serviço da cidade. 
De acordo com Ghel (2013), a distância confortável a ser percorrida por uma pessoa é muito relativa, enquanto algumas pessoas andam confortáveis durante muitos quilômetros, outras pessoas (como idosos e crianças) possuem dificuldade para se locomoverem mesmo em pequenas distâncias. Entretanto, a maiorias das pessoas estão dispostas a percorrerem cerca de 500 metros, dependendo também da qualidade do percurso. Com base nisso, definimos, para essa pesquisa, 2 círculos de influência dos conjuntos estudados, partindo do centro do conjunto, com raios de 500 metros e 1 quilômetro.

\section{RESULTADOS}

Foi realizado um levantamento da localização do conjunto Inocoop em relação à malha urbana e centro da cidade. A distância observada na imagem abaixo é de aproximadamente 3,8 $\mathrm{km}$, com uma rota sugerida. O centro da cidade, como mostrado anteriormente, abriga serviços essenciais a população, como a sede da Prefeitura, as Secretarias Municipais, a Câmera Municipal, Bancos e Comércio do município. O conjunto habitacional Jardim Panorâmico fica localizado a, aproximadamente, a 7,5 km do centro da cidade de Presidente Prudente e é possível notar que o conjunto é rodeado por alguns vazios urbanos (figura 1).
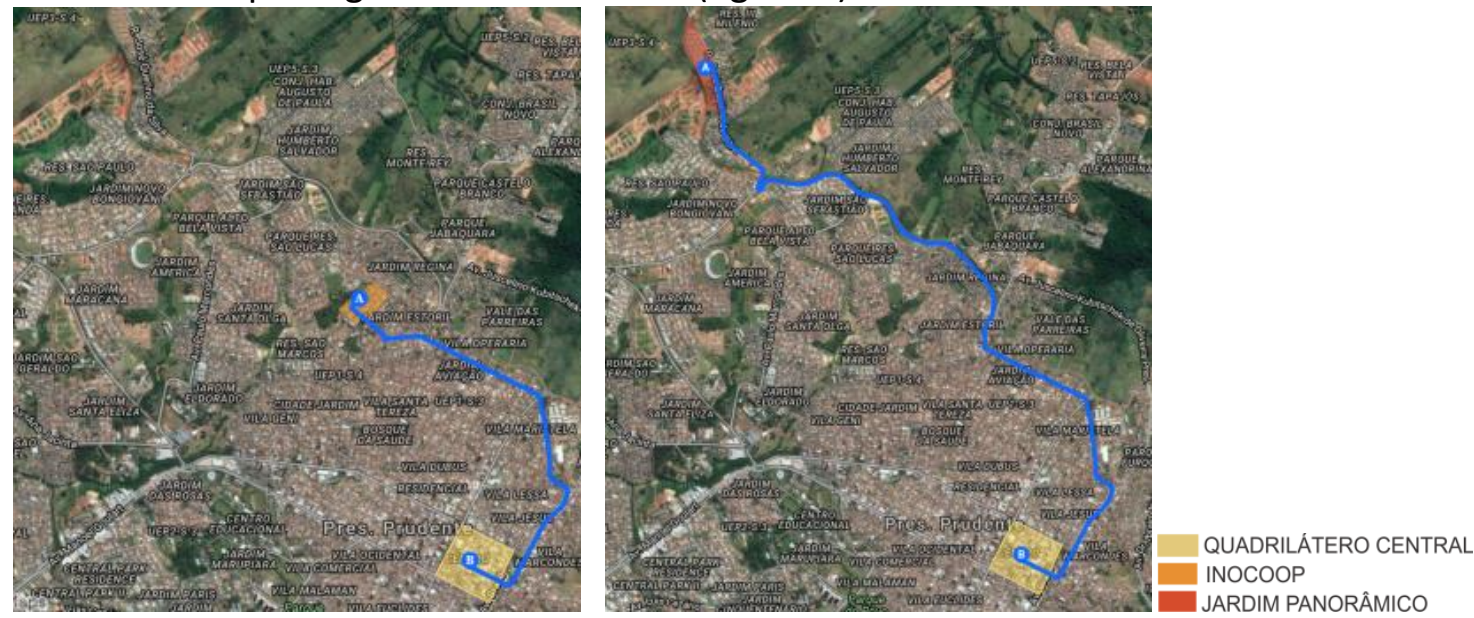

Figura 01. Comparação da relação dos conjuntos habitacionais (Inocoop e Jardim Panorâmico,respectivamente) e o centro da cidade.

Fonte: Google Earth (2016), editado pelas autoras.

Quanto às escolas da cidade, verificamos as unidades próximas (em relação ao raio de 500 m e $1 \mathrm{~km}$, citados anteriormente) ao Inocoop. É possível verificar que existe 1 escola estadual de ensino médio e ensino fundamental dentro do raio de $1 \mathrm{~km}$ a partir do centro do bairro, além de 3 escolas municipais de educação infantil e de ensino fundamental ( $1^{\circ}$ ao $5^{\circ}$ ano). Quanto ao Jardim Panorâmico, notamos que ainda não existe nenhuma escola dentro do raio estipulado para a análise, sendo que a unidade escolar mais próxima, uma escola municipal de educação infantil, esta localizada a um pouco mais de $1 \mathrm{~km}$ de distancia do centro do conjunto.

Ao analisarmos a imagem a seguir, podemos notar também que o conjunto Inocoop foi implantado na franja urbana, no limite do crescimento da cidade. Ao compararmos os bairros, percebe-se que o Jardim Panorâmico foi implantado em uma área mais distante da franja urbana, preservando grandes áreas urbanas sem utilização, ou subutilizadas (figura 2). 


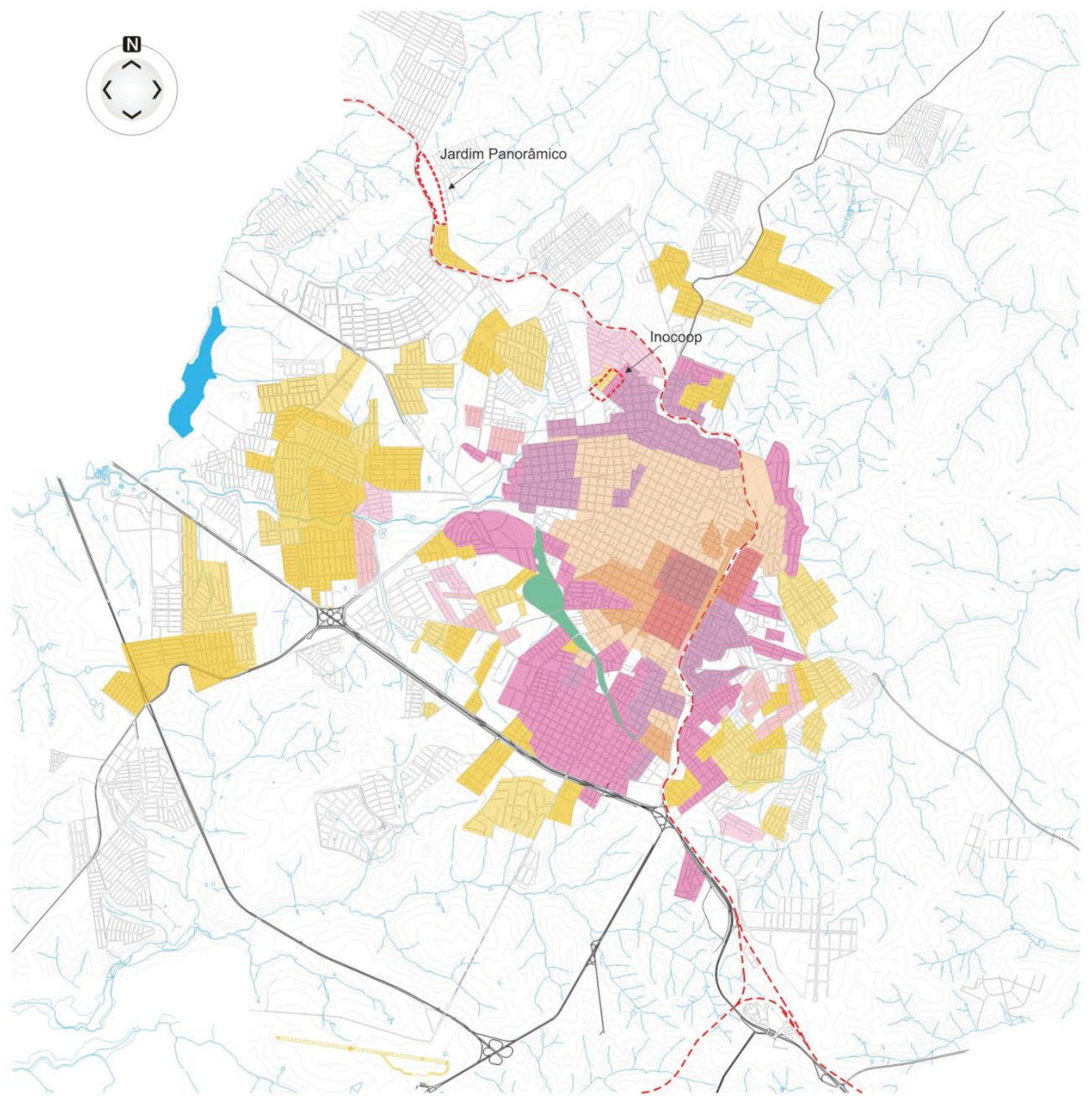

LEGENDA:
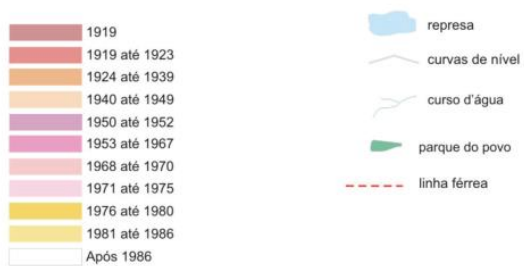

Figura 2. Expansão Urbana - 1968- 1986

Fonte: BARON (2010), editado pelas autoras.

O Conjunto Inocoop também possui mais pontos de ônibus - e linhas - do que o conjunto Jardim Panorâmico, apesar deste estar localizado mais distante da área central da cidade. Isso se repete, também, quanto aos equipamentos de Saúde, sendo que o mais próximo do Inocoop fica a 600 metros, enquanto no jardim Panorâmico a unidade de saúde mais próxima esta á 2,6 km.

Em ambos os conjuntos nota-se a não consolidação da maior parte das áreas destinadas a lazer e institucional (figura 3). 
Inocoop

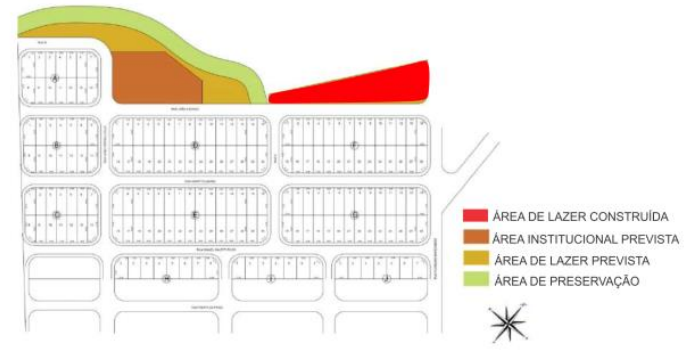

Jardim Panorâmico

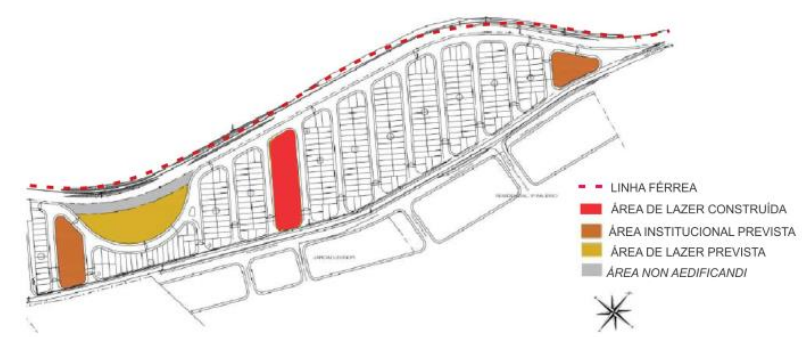

Figura 3. marcação das áreas de lazer e institucional dos conjuntos (sem escala).

Fonte: Prefeitura de Presidente Prudente, editado pelas autoras.

\section{DISCUSSÃO}

Os conjuntos habitacionais escolhidos para a realização dessa pesquisa possuem um intervalo de 30 anos entre suas construções (Inocoop em 1979 e Jardim Panorâmico em 2009). Com base nos levantamentos realizados até então, podemos notar diferenças entre eles, principalmente baseados em sua relação com a malha urbana da cidade e o quadrilátero central enquanto o Inocoop foi implantado em uma área mais próxima do centro da cidade, o Jardim Panorâmico foi construído em um local mais afastado, mesmo com a presença de grandes vazios urbanos na franja urbana. Entretanto, é possível observar alguns processos que se repetem nos dois conjuntos, cada um em sua temporalidade: as áreas verde e institucional não foram ocupadas e o surgimento de atividades comerciais não previstas, uma vez que não havia áreas destinadas ao comércio.

Porém, como o Inocoop foi executado a 30 anos e se encontra rodeado por outros bairros, consolidados na malha urbana, os moradores utilizam as áreas de lazer adjacentes, pois essas estão qualificadas.

\section{CONCLUSÕES}

A partir dos resultados dessa pesquisa é possível notar: avanços, como por exemplo, o programa atender famílias de 0 a 3 salários mínimos e retrocessos, como a dificuldade de mobilidade urbana, sendo que a implantação do conjunto se tornou mais distante do centro da cidade, onde se localizam os principais serviços e atividades urbanas.

O Inocoop apresentava uma situação urbana mais favorável a sua implantação, sem grandes vazios urbanos isolando-o da malha urbana e, o sistema viário teve continuidade, integrando-se ao já existente. O Jardim Panorâmico, por sua vez, possui grandes áreas desocupadas e o sistema viário apresenta uma única via circundando-o. Nota-se também a proximidade da linha férrea, dificultando uma possível continuidade para a expansão no sentido norte.

Percebe-se, após as discussões, a importância da escolha de áreas bem localizadas para a implantação de conjuntos habitacionais de interesse social, que possibilitem a mobilidade urbana, a utilização de equipamentos urbanos existentes, bem como áreas de lazer, além das atividades cotidianas relacionadas ao comércio e serviços. Embora, o preço da terra seja mais barato em áreas mais distantes, deveria ser também considerado os custos das infraestruturas e dos equipamentos públicos ainda não existentes no entorno próximo.

Os resultados apresentados mostram, portanto, a importância de se levar em conta os fatores urbanísticos dos projetos de implantação dos conjuntos de habitação de interesse social. qualificando o projeto urbano e a inclusão socioespacial. Espera-se que essa pesquisa possa auxiliar no entendimento e melhoramento da política habitacional de interesse social. 


\section{REFERÊNCIAS}

ABIKO, A. K. ORNSTEINS, S. W. Inserção Urbana e Avaliação Pós-Ocupação (APO) da Habitação de Interesse Social. São Paulo : FAUUSP,2002.

BARON, C. M. P. Cidade e habitação em Presidente Prudente: 1964- 1986. São Carlos, 2010. Tese (Doutorado-Programa de Pós-Graduação em Arquitetura e Urbanismo e Área de Concentração em Teoria e História da Arquitetura e do Urbanismo). Escola de Engenharia de São Carlos da Universidade de São Paulo, 2010.

BARON, C. M. P. e SILVA, M. L. (2014) As Políticas Habitacionais e o Direito à Cidade: a produção dos conjuntos habitacionais em Presidente Prudente In: III Encontro da Associação Nacional de Pesquisa e Pós-graduação em Arquitetura e Urbanismo arquitetura, cidade e projeto: uma construção coletiva, 2014, São Paulo. Anais do III ENANPARQ: arquitetura, cidade e projeto: uma construção coletiva. São Paulo e Campinas: Universidade Presbiteriana Mackenzie e Pontifícia Universidade Católica de Campinas, 2014. v.1. p.1-10

FERREIRA, J.S.W. Produzir casas ou construir cidades? Desafios para um novo Brasil urbano: parâmetros de qualidade para a implementação de projetos habitacionais e urbanos. São Paulo. Editora FUPAM, 2012.

FINEP-GAP. Habitação Popular - Inventário da ação governamental, vol 1. Rio de Janeiro, 1983.

FINEP-GAP. Habitação Popular - inventário da ação governamental. Vol. 2 Complementação, Rio de Janeiro, 1984/1986.

GEHL, Jan. Cidades para pessoas. SP: Perspectiva, 2013. 